\title{
МАКРОЭКОНОМИЧЕСКАЯ СТАБИЛЬНОСТЬ НАЦИОНАЛЬНОЙ ЭКОНОМИКИ В МОДЕЛИ «ОТКРЫТОЙ ЭКОНОМИКИ» Д.М. ФЛЕМИНГА
}

\author{
(c) 2019 Лихачев Михаил Олегович \\ доктор экономических наук, доцент, профессор кафедры Экономической теории и менеджмента \\ Московский педагогический государственный университет, Россия, Москва \\ E-mail: olegmix71@mail.ru
}

В статье рассматриваются базовые принципы кейнсианской модели «открытой экономики», разработанной Д.М. Флемингом. Автор статьи рассматривает теоретическую структуру модели, а также практические выводы относительно использования различных видов макроэкономической политики государства для обеспечения стабильности национальной экономики, находящейся под воздействием международных товарных и финансовых потоков.

Ключевые слова: макроэкономическое равновесие, национальная экономика, открытая экономика, кейнсианство, модель Д. М. Флеминга, макроэкономическая политика, бюджетно-налоговая политика, денежно-кредитная политика, макроэкономическая стабильность.

Модели открытой экономики представляют собой класс макроэкономических моделей, концентрирующих приоритетное внимание на процессе взаимодействия национальной экономики с внешним миром [1]. В современных условиях, когда национальные экономики подавляющего большинства стран плотно включились в систему международных экономических отношений, эта проблематика является очень актуальной. Однако события мирового кризиса 2008 г. и, последовавшей за ним, глобальной рецессии, показали, что традиционные неоклассические представления о гибкости цен и валютного курса как ведущих адаптационных механизмах, обеспечивающих стабильность национальной экономики в условиях «внешних шоков» не являются адекватными. В свете этого вновь актуальными становятся кейнсианские подходы к анализу макроэкономических проблем и, в том числе, к проблеме макроэкономической стабильности национальной экономики $[4 ; 7 ; 8 ; 9]$.

Базовой кейнсианской моделью открытой экономики является модель Д. М. Флеминга, разработанная еще в 60-х гг. XX в. [2; 3]. Однако, для понимания исходных постулатов кейнсианского анализа проблем открытой экономики целесообразно обратиться именно к этой модели как к первоисточнику.

\section{Модель Д. М. Флеминга}

Исходной точкой анализа для Д.М. Флеминга является тождество национальных счетов. Он представляет это тождество как сумму внутренних расходов и чистого экспорта:

$$
\mathrm{Y}=\mathrm{Z}+\mathrm{NX}
$$

Где $\mathrm{Z}$ - сумма потребительских расходов, инвестиций и государственных расходов $(\mathrm{Z}=\mathrm{C}+\mathrm{I}+\mathrm{G})$, составляющих внутренние расходы экономики.

Равновесный объем потребительских расходов определяется на основе кейнсианской функции потребления:

$$
\mathrm{C}=\mathrm{C}_{0}+\operatorname{MPC}\left(1-T_{y}\right) Y
$$

Где $\mathrm{C}_{0}$ - автономные потребительские расходы, $\mathrm{T}_{\mathrm{y}}$ - доля налогов в национальном доходе, а МРC - предельная склонность к потреблению.

Равновесный объем инвестиций представлен линейной функцией, устанавливающей обратную зависимость инвестиций от ставки процента:

$$
\mathrm{I}=\mathrm{I}_{0}-\mathrm{I}^{\prime}(\mathrm{i}) \mathrm{i}
$$

Где $\mathrm{I}_{0}$ - автономные инвестиции, a $\mathrm{i}$ - номинальная процентная ставка. 
Государственные расходы рассматриваются в качестве экзогенной переменной, а равновесный объем чистого экспорта представлен как отрицательная функция от внутренних расходов и положительная от величины номинального валютного курса в обратной котировке:

$$
\mathrm{NX}=\mathrm{NX}_{0}-\mathrm{NX}^{\prime}(\mathrm{z})(\mathrm{C}+\mathrm{I}+\mathrm{G})+\mathrm{NX}\left(\frac{1}{\mathrm{e}}\right) \frac{1}{\mathrm{e}}
$$

Где $\mathrm{NX}_{0}-$ автономная величина чистого экспорта, а е - валютный курс в прямой котировке.

Кроме того, ставка процента определяется как величина, зависимая от скорости обращения денег (v), то есть от отношения номинального национального дохода к денежной массе (M):

$$
\mathrm{i}=\mathrm{i}^{\prime}(\mathrm{v}) \frac{\mathrm{Y}}{\mathrm{M}}
$$

Сальдо платежного баланса выражается как сумма чистого экспорта товаров и услуг и чистого импорта капитала (разность импорта и экспорта капитала) (NIK). Причем чистый импорт капитала рассматривается как величина, напрямую зависящая от ставки процента:

$$
\mathrm{NIK}=\mathrm{NIK}_{0}+\mathrm{NIK}^{\prime}(\mathrm{i}) \mathrm{i}^{\prime}(\mathrm{v}) \frac{\mathrm{Y}}{\mathrm{M}}
$$

Где $\mathrm{NIK}_{0}$ - величина автономного чистого импорта капитала.

Сальдо платежного баланса является суммой чистого экспорта и чистого импорта капитала.

\section{Макроэкономическая политика в услови- ях фиксированного валютного курса}

Система с фиксированным курсом национальной валюты предполагает, что величина реального валютного курса может корректироваться только за счет изменения уровня цен. Однако Д.М. Флеминг разрабатывает свою модель для краткосрочного периода и исключает изменение уровня цен из рассмотрения. Это приводит к тому, что для системы с фиксированным курсом национальной валюты Д.М. Флеминг вынужден признать возможность установления внешнего равновесия при неравном нулю сальдо платежного баланса. Это допущение является неизбежным следствием исключения из анализа изменения уровня цен. Ведь при неизменном уровне цен и фиксированном номинальном курсе валюты реальный курс, если он изначально не был установлен на уровне, обеспечивающем нулевое сальдо платежного баланса, никак не может приблизиться к этому уровню.

Влияние государственных расходов на величину национального дохода и сальдо платежного баланса может быть представлено формулами (7) и (8).

Зависимость национального дохода от величины государственных расходов является положительной. Характер зависимости сальдо платежного баланса от величины государственных расходов будет зависеть от эластичности ставки процента по величине национального дохода при неизменном количестве денег и от подвижности капитала, то есть от эластичности чистого импорта капитала по величине ставки процента. При заданной эластичности ставки процент главную роль будет играть подвижность капитала. Если подвижность капитала является высокой, зависимость между сальдо платежного баланса и государственными расходами будет прямой, поскольку реакция чистого импорта капитала на изменение ставки процента в результате изменения национального дохода и скорости обращения денег будет сильнее противоположной ей по знаку реакции чистого экспорта товаров и услуг на изменение внутренних расходов. Если же параметр, характеризующий подвижность капитала невысок, реакция чистого экспорта будет на изменение внутренних расходов будет превалировать над реакцией чистого импорта капитала на изменение ставки процента и сальдо платежного баланса будет изменяться в обратном отношении к изменению государственных расходов.

$$
\begin{aligned}
& \frac{d Y}{d G}=\frac{1-N^{\prime}(z)}{1-\left(1-N^{\prime}(z)\right)\left(M P C(1-T y)-\frac{I^{\prime}(i) i^{\prime}(v)}{M}\right)} \\
& \frac{d N X}{d G}+\frac{d N I K}{d G}=\left(N^{\prime} K^{\prime}(i)-\frac{N X^{\prime}(z) M}{i^{\prime}(v)\left(1-N X^{\prime}(z)\right)}\right) \frac{i^{\prime}(v) d Y}{M d G}
\end{aligned}
$$


Влияние изменения денежной массы на параметры системы с фиксированным валютным курсом можно представить формулами (9) и (10).

Воздействие денежной массы на объем национального дохода является положительным, а на величину сальдо платежного баланса отрицательным, поскольку зависимость ставки процента от величины денежной массы (di/dM) является обратной и имеет отрицательный знак. Увеличение денежной массы ведет к расширению спроса на импорт, снижает чистый экспорт и, одновременно, снижает процентную ставку, что приводит к сокращению величины чистого импорта капитала.

Однако, следует учитывать, что благодаря специфическим особенностям функционирования системы с фиксированным валютным курсом эффекты денежной политики если не полностью, то в значительной мере нейтрализуются операциями Центрального Банка, направленными на поддержание установленного курса национальной валюты. В силу этого в условиях фиксированного курса бюджетно-налоговая политика играет ведущую роль по сравнению с денежно-кредитной политикой государства. Любое изменение платежного баланса вызывает соответствующее изменение денежной массы в результате валютных операций, проводимых Центральным Банком. При положительном сальдо платежного баланса центральный банк увеличивает свои валютные резервы скупая избыток иностранной валюты и тем самым увеличивает предложение национальной. А при отрицательном сальдо, Центральному Банку приходится распродавать свои валютные резервы, ликвидируя излишек предложения национальной валюты. Поэтому любое изменение денежной массы, поскольку оно отражается на величине платежного баланса, уравновешивается обратным движением денежной массы в связи с валютными операциями Центрального
Банка. Поэтому автономная денежно-кредитная политика является если не нейтральным, то, во всяком случае, слабым инструментом воздействия на величину национального дохода и сальдо платежного баланса.

Бюджетно-налоговая политика, поскольку она влияет на величину сальдо платежного баланса, непосредственно взаимосвязана с денежно-кредитной политикой. Если влияние государственных расходов на величину сальдо платежного баланса является положительным, оно будет вызывать однонаправленное увеличение денежной массы. Следовательно, действие государственных расходов на величину национального дохода будет дополнительно усиливаться за счет воздействия денежной массы. Однако, если сальдо платежного баланса находится в обратной зависимости от величины государственных расходов (это происходит при малой подвижности капитала), изменение денежной массы, индуцированное изменением государственных расходов будет противоположно ему по знаку и, следовательно, будет ослаблять воздействие государственных расходов на величину национального дохода.

В системе с плавающим курсом национальной валюты, платежный баланс будет уравновешиваться за счет изменения величины валютного курса. Следовательно, адаптационными параметрами системы будут уже не национальный доход и сальдо платежного баланса, которое при плавающем курсе в равновесном состоянии всегда равно нулю, а национальный доход и курс национальной валюты.

Воздействие изменения величины государственных расходов на национальный доход может быть представлено выражением (11).

Влияние государственных расходов является положительным. Однако оно может существенно ослабляться за счет высокой подвижности капитала. Если чистый импорт капитала сильно

$$
\begin{aligned}
& \frac{d Y}{d M}=\frac{I^{\prime}(i) i^{\prime}(v) Y}{M^{2}}\left(\frac{1}{\frac{1}{1-N^{\prime}(z)}-M^{\prime} C(1-T y)-\frac{I^{\prime}(i) i^{\prime}(v) Y}{M^{2}}}\right) \\
& \frac{d N X}{d M}+\frac{d^{\prime} I K}{d M}=\frac{N^{\prime}(z) d Y}{1-N^{\prime}(z) d M}+N^{\prime}(i) \frac{d i}{d M} \\
& \frac{d Y}{d G}=\frac{1}{1-M^{\prime}(1-T y)-\frac{\left(I^{\prime}(i)+N^{\prime} K^{\prime}(i)\right) i^{\prime}(v)}{M}}
\end{aligned}
$$


реагирует на изменение ставки процента, это ведет к столь же резкому изменению номинального курса валюты, а вместе с ним к изменению величины чистого экспорта товаров и услуг в направлении противоположном изменению государственных расходов. В результате этого сохраняется равновесие платежного баланса, но эффект от изменения государственных расходов значительно ослабляется. Поэтому в условиях плавающего курса бюджетно-налоговая политика играет второстепенную роль в процессе регулирования величины национального дохода.

Воздействие государственных расходов на равновесное значение номинального валютного курса можно, в свою очередь, представить выражением (12). Это выражение еще более ярко демонстрирует ту же закономерность, что и предыдущее. Рост государственных расходов, поскольку он содействует увеличению потребительских расходов, ведет к снижению чистого экспорта и номинального валютного курса. Но поскольку он вызывает рост скорости обращения денег и повышение ставки процента, он будет содействовать росту чистого импорта капитала и повышению номинального курса национальной валюты. Поэтому курс национальной валюты не может понизиться настолько, чтобы уравновесить предшествующее снижение чистого экспорта товаров и услуг, что и вызывает ослабление эффекта от увеличения государственных расходов. Аналогично, при снижении государственных расходов сокращение внутреннего спроса на импорт будет стимулировать увеличение чистого экспорта и рост курса национальной валюты. Однако, снижение скорости обращения денег и ставки процента будет вызывать снижение величины чистого импорта капитала, что в свою очередь будет способствовать снижению курса национальной валюты. Поэтому рост курса национальной валюты будет недостаточным, чтобы вернуть величину чистого экспорта к начальному уровню.

Д.М. Флеминг допускает даже возможность такого варианта, когда эластичность ставки процента по скорости обращения денег и подвижности капитала так велики, что перевешивают влияние внутренних расходов на величину валютного курса. В этом случае государственные расходы окажут положительное влияние на величину валютного курса. В результате, рост государственных расходов будет вызывать сокращение чистого экспорта, что еще более ограничит влияние государственных расходов на величину национального дохода [5].

Денежно-кредитная политика в системе с плавающим курсом является ведущим инструментом государственного регулирования. Она оказывает более сильное влияние на величину национального дохода, которое не ослабляется, но, наоборот, усиливается подвижностью капитала. В этом можно убедиться, проанализировав математическое выражение (13) влияния изменения денежной массы на национальный доход.

Если денежная масса увеличивается, то это ведет к снижению ставки процента, что положительно отражается на величине инвестиций. Сокращается чистый импорт капитала и снижается валютный курс, что вызывает увеличение чистого экспорта. А при сокращении денежной массы, рост процентной ставки будет, одновременно, содействовать сокращению инвестиций и росту чистого импорта капитала, что означает повышение валютного курса и сокращение чистого экспорта. Таким образом, оба источника влияния денежной массы на национальный доход действуют в одном направлении, что содействует усилению эффекта кредитно-денежной политики.

Этот вывод можно подтвердить, проанализировав выражение (14), отражающее влияние денежной массы на величину валютного курса.

$$
\begin{aligned}
& \frac{d \frac{1}{e}}{d G}=\frac{1}{N X^{\prime}\left(\frac{1}{e}\right)}\left(N X^{\prime}(z)+\left(N X^{\prime}(z) M P C(1-T y)-\left(N X^{\prime}(z) I^{\prime}(i)+N I K^{\prime}(i)\right) \frac{i^{\prime}(v)}{M}\right.\right. \\
& \frac{d Y}{d M}=\frac{\left(I^{\prime}(\mathrm{i})+N^{\prime} K^{\prime}(\mathrm{i})\right) \mathrm{i}^{\prime}(\mathrm{v}) \mathrm{Y}}{\mathrm{M}^{2}}\left(\frac{1}{1-\mathrm{MPC}(1-\mathrm{Ty})-\frac{\left(\mathrm{I}^{\prime}(\mathrm{i})+\mathrm{NIK}^{\prime}(\mathrm{i})\right) \mathrm{i}^{\prime}(\mathrm{v})}{\mathrm{M}}}\right) \\
& \frac{\mathrm{d} \frac{1}{\mathrm{e}}}{\mathrm{dM}}=\frac{1}{\mathrm{NX}\left(\frac{1}{\mathrm{a}}\right)}\left(\mathrm{NX}^{\prime}(\mathrm{z}) \mathrm{MPC}(1-\mathrm{Ty})-\left(\mathrm{NX}^{\prime}(\mathrm{z}) \mathrm{I}^{\prime}(\mathrm{i})+\mathrm{NIK}^{\prime}(\mathrm{i})\right) \frac{\mathrm{i}^{\prime}(\mathrm{v})}{\mathrm{M}}\left(\frac{\mathrm{dY}}{\mathrm{dM}}-\frac{\mathrm{Y}}{\mathrm{M}}\right)\right)
\end{aligned}
$$


Очевидно, что если, что явно следует из выражения $\mathrm{dY} / \mathrm{dM}<\mathrm{Y} / \mathrm{M}$, определяющего влияние денежной массы на величину национального дохода, то величина валютного курса в прямой котировке будет находиться в обратной зависимости от денежной массы. Рост денежной массы будет вызывать снижение валютного курса и рост чистого экспорта товаров и услуг и, следовательно, усиливать воздействие денежно-кредитной политики на величину национального дохода. И, наоборот, сокращение денежной массы вызовет рост курса национальной валюты и сокращение чистого экспорта, что также усилит эффект воздействия денежно-кредитной политики на величину национального дохода.

\section{Макроэкономическая политика в систе- ме с плавающим валютным курсом}

В системе с плавающим курсом валюты денежно-кредитная политика является более сильным инструментом, чем бюджетно-налоговая. Однако использование денежно-кредитной политики, которое дает столь сильный эффект в краткосрочном плане, может в долгосрочном плане обернуться усилением инфляционных тенденций [6]. Поэтому более целесообразным является определенное сочетание денежно-кредитной и бюджетно-налоговой политики для достижения желаемых параметров равновесия. Так денежно-кредитная политика может быть использована для того, чтобы нивелировать эффект воздействия государственных расходов на процентную ставку. Если, например, правительство увеличивает государственные расходы, оно может, одновременно, увеличить денежную массу таким образом, чтобы не допустить увеличения скорости обращения денег и повышения ставки процента. Это позволит не допустить увеличения чистого импорта капитала и избежать его повышающего воздействия на валютный курс. В результате, эффект ослабляющий воздействие государственных расходов на величину национального дохода будет нейтрализован. Этот вариант более предпочтителен еще и потому, что денежно-кредитная политика более сильно влияет на параметры платежного баланca, а бюджетно-налоговая политика - на величину национального дохода. Это связано с тем, что государственные расходы значительно сильнее воздействуют на потребительские расходы, чем на ставку процента, от которой зависят инвестиции и чистый импорт капитала. А денежно-кредитная политика, наоборот, отражается, прежде всего, на ставке процента и, следовательно, на чистом импорте капитала и валютном курсе. Поэтому бюджетно-налоговая политика является более эффективной для коррекции параметров внутреннего равновесия, а денежно-кредитная политика более эффективна при управлении параметрами внешнего равновесия.

Таким образом, Модель Д. М. Флеминга показывает, что макроэкономическая стабильность национальной экономики и эффективность государственной макроэкономической политики во многом зависит от уровня мобильности товарных и финансовых потоков и от способности государства их контролировать [10]. Это требует создания специфической инфраструктуры в виде соответствующей системы торговой политики и финансово-банковской системы, которые способны регулировать направления и темпы обменных процессов между национальной экономикой и внешним миром.

\section{Библиографический список}

1. Блауг М. Экономическая мысль в ретроспективе. М.: Дело ЛТД.,1994.

2. Флеминг Д. М. Внутренняя финансовая политика при фиксированном и плавающем обменных курсах // Этот изменчивый обменный курс.- М. 2001. с. 165-178.

3. Флеминг Д.М. Плавающий обменный курс, асимметричная интервенция и управление международной ликвидностью // Этот изменчивый обменный курс.- М. 2001. С. 179-206.

4. Хансен Э. Экономические циклы и национальный доход. / Классики кейнсианства. Т. 1, 2. М.: Экономика, 1997. C. 202-415.; 1-431.

5. Drumond C. E., De Jesus C.S. Monetary and fiscal policy interactions in a post Keynesian open-economy model // Journal of Post Keynesian Economics. Volume 39, 2016 - Issue 2. pp. 172-186.

6. Madsen J.B. Pricing-To-Market and the Efficiency of Macroeconomic Policies in Open Economies with Floating Exchange Rates // Journal of Post Keynesian Economics. Volume 19, 1996. pp. 225-242. 
7. Paula L. F., Fritz B., Prates D.M. Keynes at the periphery: Currency hierarchy and challenges for economic policy in emerging economies // Journal of Post Keynesian Economics. 2017. V. 40. pp. 183-202.

8. Rotheim R.J. New keynesian economics/post keynesian alternatives. New York. 2003.

9. Stiglitz J. Globalization and discontent. New York. 2002.

10. Sarantis N. The Mundell-Fleming Model with Perfect Capital Mobility and Oligopolistic Pricing // Journal of Post Keynesian Economics. Volume 9. 1986, pp. 138-148. 